\title{
COMPDYN 2015
}

$5^{\text {th }}$ International Conference on

Computational Methods in Structural Dynamics and Earthquake Engineering

\section{PROCEEDINGS \\ Volume I}

M. Papadrakakis, V. Papadopoulos, V. Plevris (Eds)

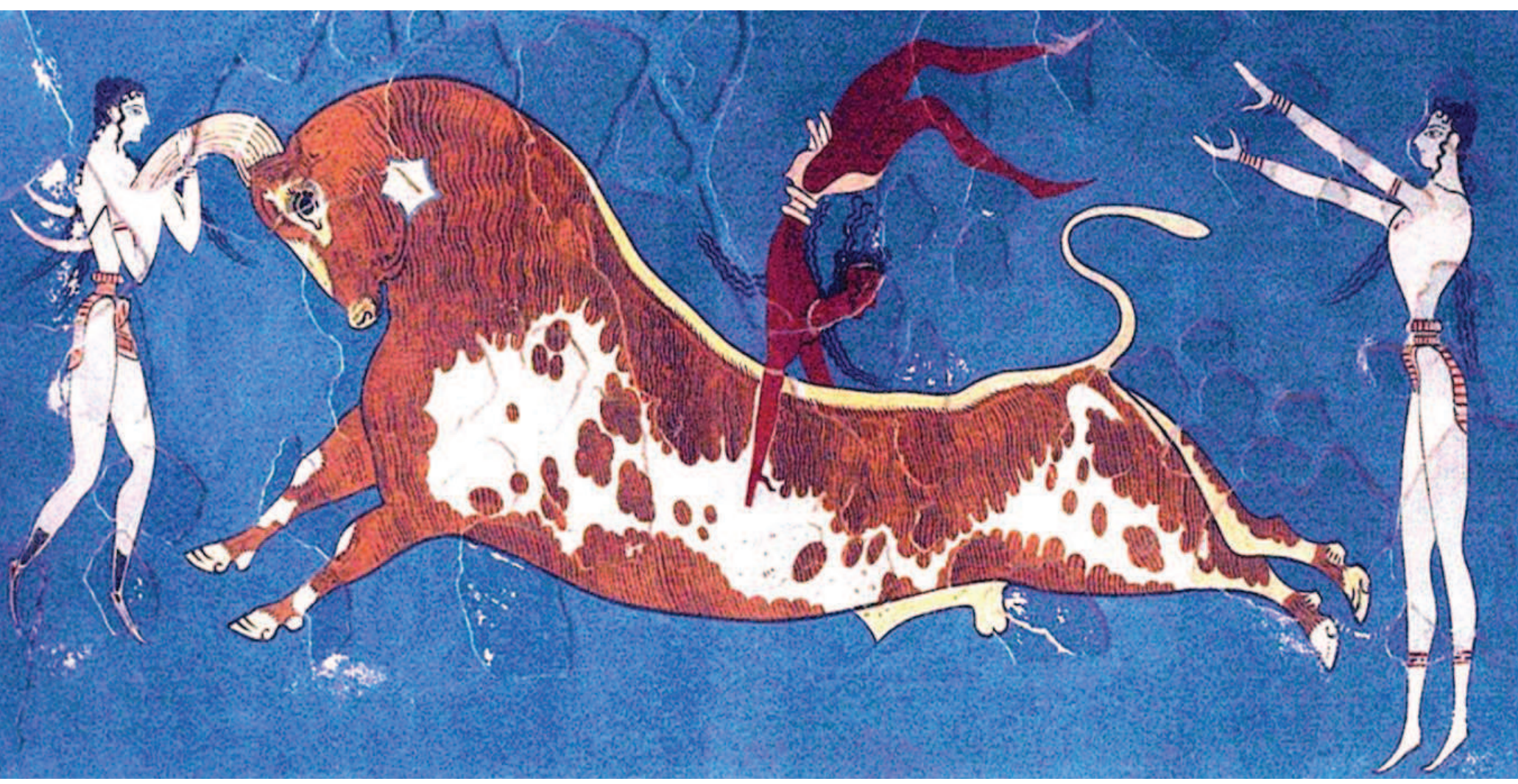




\title{
SEISMIC RESPONSE ANALYSIS OF A GEOGRID REINFORCED WALL CONSTRUCTED WITH RECYCLED CONSTRUCTION AND DEMOLITION WASTE
}

\author{
Castorina Silva Vieira ${ }^{1}$ \\ ${ }^{1}$ University of Porto - Faculty of Engineering - Civil Engineering Department \\ R. Dr Roberto Frias, s/n 4200-465 Porto, Portugal \\ e-mail: cvieira@fe.up.pt
}

Keywords: Geogrids, Construction and Demolition Wastes, Seismic loading, Shear strength parameters

\begin{abstract}
Over the last years the environmental sustainability has been demanding a progressive increase in the waste valorisation in construction. The valorisation of Construction and Demolition Wastes (C\&DW) reduces the use of natural resources (non-renewable) and, simultaneously, avoids congesting landfills with inert wastes coming from buildings and other infrastructures. Although some studies have been carried out on the use of recycled $C \& D W$ in construction industry, their valorisation as fill material in geosynthetic reinforced structures is almost an unexplored field. A research project aiming to contribute to the sustainable application of recycled $C \& D W$ as backfill material in geosynthetic reinforced structures, is being developed at University of Porto, Portugal. Preliminary results of this research are presented in this paper.
\end{abstract}

In this work the two-dimensional finite difference program Fast Lagrangian Analysis of Continua (FLAC) was used to model the behaviour of a geogrid reinforced wall, constructed in Brazil, with recycled $C \& D W$. The wall is $3.6 \mathrm{~m}$ high and was constructed at an inclination of 1:4.3 (wall batter of $13^{\circ}$ from vertical). The backfill was reinforced with six layers of geogrid placed at $0.6 \mathrm{~m}$ of vertical spacing and $2.52 \mathrm{~m}$ long. The seismic response of a similar wall, hypothetically constructed with recycled $C \& D W$ coming from a Portuguese recycling plant, is also evaluated.

An earthquake ground motions artificially generated for the greatest seismicity area of Portugal was considered as seismic input. Two constitutive models were used to model the backfill C\&DW material: the Mohr-Coulomb model and a Strain-Softening model. Permanent displacements of the wall face, settlements and reinforcement tensile forces are analysed and discussed. The numerical simulations have shown that the possible decrease of the backfill shear strength during cyclic loading is an important issue to be studied more closely. Notwithstanding it was concluded that a well compacted and drained recycled $C \& D W$ can be used as fill material in geosynthetic reinforced structures. 


\section{INTRODUCTION}

The reduction of non-renewable natural resources exploration has been a constant concern relating to the preservation of the environment that, simultaneously, encourages the use of alternative materials. Thus, over the last years the environmental sustainability has been demanding a progressive increase in the waste valorisation in construction.

The Construction and Demolition Wastes (C\&DW) are wastes derived from construction, reconstruction, cleaning of the work site and earthworks, demolition and collapse of buildings, maintenance and re-habilitation of existing constructions. The composition of the C\&DW is variable depending on the construction type and construction processes that predominate in the area. They include: concrete, bricks, tiles, soils, rocks, vegetation, materials from roads maintenance and a wide variety of other materials.

Although some studies have been carried out on the application of recycled construction and demolition wastes, their purposes are mainly the production of aggregates for use in concrete and in base layers of transportation infrastructures. As regards the application of C\&DW in geotechnical works, it has been verified that the valorisation is performed mostly in road construction, particularly in base and sub-base layers of the infrastructures. Outside the scope of road infrastructures, references to C\&DW applications in embankments are scarse. The valorisation of Recycled C\&DW in geosynthetic reinforced structures is almost an unexplored field.

This paper presents results of a research project under development at University of Porto, aiming to contribute to the sustainable application of recycled C\&DW in geosynthetic reinforced structures, proving the good performance of these structures.

A preliminary calibration analysis using instrumentation data of a geogrid reinforced wall constructed with C\&DW as backfill material [1] is presented. Based on results of direct shear tests carried out on recycled C\&DW and presented by [2], the seismic behaviour of a similar reinforced wall, hypothetically constructed with the characterized C\&DW material, is also evaluated. Several numerical analyses were carried out, considering distinct assumptions related to the backfill shear strength parameters.

\section{BRIEF DESCRIPTION OF FLAC CODE AND SEISMIC LOADING INPUT}

FLAC is an explicit finite difference program that performs a Lagrangian analysis. The finite difference method is perhaps the oldest numerical technique used for the solution of sets of differential equations, given initial values and/or boundary values [3]. For dynamic analyses the full equations of motion are solved using lumped gridpoint masses derived from the real density of surrounding zones (rather than fictitious masses used for static solution). Each triangular sub-zone contributes one-third of its mass (computed from zone density and area) to each of the three associated gridpoints. The final gridpoint mass is then divided by two in the case of a quadrilateral zone that contains two overlays. In finite-element terminology, FLAC uses lumped masses and a diagonal mass matrix [3].

In FLAC, the dynamic input can be applied as an acceleration history, as a velocity history, as a stress (or pressure) history or as a force history. Dynamic input can be applied either in the $\mathrm{x}$ or $\mathrm{y}$ directions corresponding to the xy axes for the model, or in the normal and shear directions to the model boundary.

In the dynamic analyses presented in this paper, two constitutive models were used: the Mohr-Coulomb model and a Strain-Softening model. 
In the implementation of the Mohr-Coulomb model in FLAC, principal stresses $\sigma_{1}, \sigma_{2}, \sigma_{3}$ are used, being the out-of-plane stress, $\sigma_{\mathrm{zz}}$, recognized as one of these. With the ordering convention $\sigma_{1} \leq \sigma_{2} \leq \sigma_{3}$ (compressive stresses are negative), the failure criterion for this model is represented in the plane $\left(\sigma_{1}, \sigma_{3}\right)$ as illustrated in Figure 3.

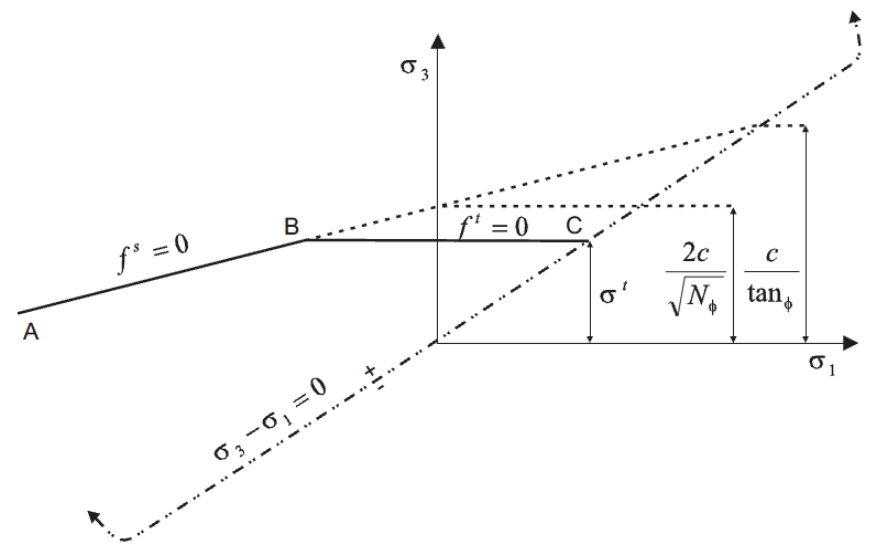

Figure 1: Mohr-Coulomb failure criterion in FLAC [3].

The failure envelope is defined from point A to point B (Figure 3) by the Mohr-Coulomb yield function:

$$
\mathrm{f}^{\mathrm{s}}=\sigma_{1}-\sigma_{3} \mathrm{~N}_{\phi}+2 \mathrm{c} \sqrt{\mathrm{N}_{\phi}}
$$

and from $\mathrm{B}$ to $\mathrm{C}$ by a tension yield function of the form:

$$
\mathrm{f}^{\mathrm{t}}=\sigma^{\mathrm{t}}-\sigma_{3}
$$

where $\phi$ is the soil friction angle, $c$ is the cohesion, $\sigma^{t}$ is the tensile strength and $\mathrm{N}_{\phi}$ is defined as:

$$
\mathrm{N}_{\phi}=\frac{1+\sin \phi}{1-\sin \phi}
$$

The tensile strength of the material, $\sigma^{t}$, cannot exceed the maximum value given by:

$$
\sigma_{\max }^{\mathrm{t}}=\frac{\mathrm{c}}{\tan \phi}
$$

The Strain-Hardening/Softening model is based on the Mohr-Coulomb model with nonassociated tension flow rules. The difference lies in the possibility that cohesion, friction, dilatation and tensile strength may harden or soften after the onset plastic yield [3]. The user can define the variation of the cohesion, friction and dilation as a function of the plastic shear strain. The variation of the tensile strength can also be prescribed in terms of plastic tensile strength. The code measures the total plastic shear and tensile strains at each timestep and causes the model properties to conform to the user-defined functions.

An earthquake ground motion artificially generated [4], according to Portuguese National Annexes (PNA) of Eurocode 8, for the greatest seismicity area of Portugal, considering seismic action type 2 (earthquake with moderate magnitude and small focal distance - close 
earthquake) and ground type B (deposits of very dense sand, gravel or very stiff clay), was considered as seismic input. According to the PNA of Eurocode 8 for the greatest seismicity area, the peak ground acceleration on type B ground is $2.7 \mathrm{~m} / \mathrm{s}^{2}$ for a close earthquake (Figure 2). The duration of the stationary part of the accelerograms is equal to 10 seconds. The Fourier spectrum for the accelerogram presented in Figure 2(a) is plotted in Figure 2(b). This graph indicates that the highest frequency is lower than approximately $20 \mathrm{~Hz}$. Before applying the seismic input motion, it was filtered to remove frequencies above the maximum frequency that can be modelled accurately.
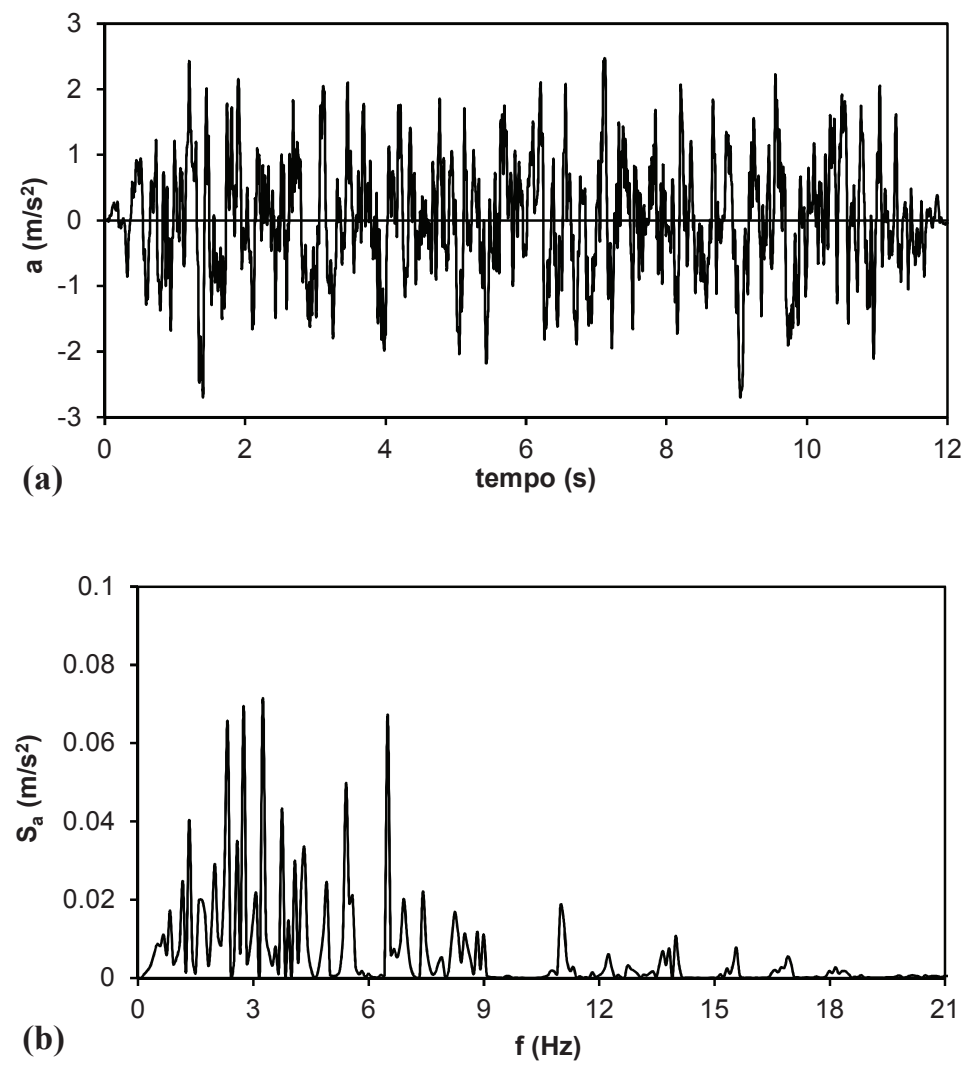

Figure 2: Seismic input motion: a) artificial accelerogram; b) Fourier spectrum

\section{CALIBRATION STRUCTURE FOR STATIC LOADING}

Before running any dynamic analysis, a preliminary calibration analysis was carried out using instrumentation data of a geogrid reinforced wall constructed with C\&DW as backfill material. Santos et al [1] report the performance of an instrumented $3.6 \mathrm{~m}$ high wrapped face geogrid reinforced wall constructed with C\&DW. The foundation of the test wall is a naturally collapsible soil that is common in Brazil (Figure 2). The wall was constructed in a reinforced masonry block container and the wrapped-face was constructed at an inclination of 1:4.3 (horizontal:vertical). The backfill was reinforced with six layers of geogrid placed at $0.6 \mathrm{~m}$ vertical spacing and $2.52 \mathrm{~m}$ long [1]. Based on the results presented by [1] an axial tensile stiffness of $200 \mathrm{kN} / \mathrm{m}$ was assumed for the geogrids .

The wall was instrumented with topographic markers, vertical and horizontal stress cells and strain gauges in the reinforcements. An inclinometer was also installed close to the wall toe to monitor the displacements of the foundation (Figure 3). 
The wall was constructed in the Foundation and Field Investigation Site of the University of Brasilia. Based on field investigations, the foundation soil (porous collapsible soil) was divided in three layers $[1,5]$. The main parameters considered for the foundation layers and for the C\&D material are presented in Table 1. Following the description presented by [5], layer 1 (immediately bellow the wall) was considered $2 \mathrm{~m}$ high and layers 2 and 3 with thickness of $3 \mathrm{~m}$ and $2 \mathrm{~m}$, respectively. A rigid layer $1 \mathrm{~m}$ high was also considered at the base of the model.

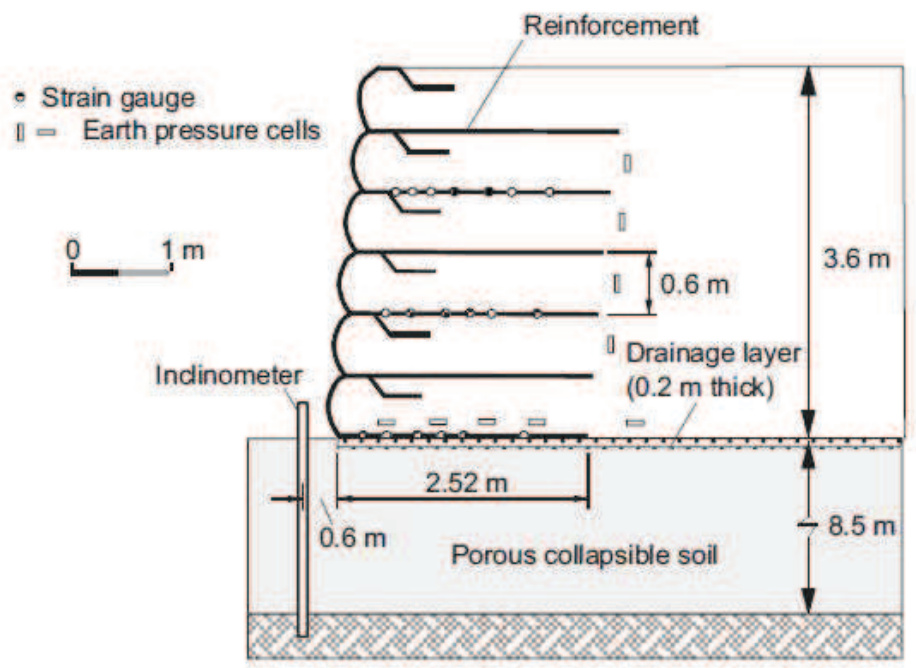

Figure 3: Cross section of the experimental geogrid reinforced wall presented by Santos et al. [1].

\begin{tabular}{llllll}
\hline Soil & $\gamma\left(\mathrm{kN} / \mathrm{m}^{3}\right)$ & $\mathrm{c}^{\prime}(\mathrm{kPa})$ & $\phi^{\prime}\left({ }^{\circ}\right)$ & $\mathrm{E}(\mathrm{MPa})$ & $v$ \\
\hline Foundation - layer 1 & 16.7 & 30 & 26 & 50 & 0.3 \\
Foundation - layer 2 & 17.3 & 19 & 30 & 50 & 0.3 \\
Foundation - layer 3 & 18.3 & 37 & 26 & 60 & 0.3 \\
Backfill - C\&D & 19.5 & 2 & 35.7 & 30 & 0.3 \\
\hline
\end{tabular}

Table 1. Foundation and backfill parameters considered in the calibration model.

The geometry of the model and the numerical grid is illustrated in Figure 4. The reinforcement layers were modelled using linear elasto-plastic cable elements with negligible compressive strength. The tensile yield strength was taken equal to $20 \mathrm{kN} / \mathrm{m}$.

The interface between the reinforcement and the soil was modelled by a grout material. The interface shear strength was considered dependent of the backfill shear strength. A coefficient of interaction of 0.7 was admitted.

Figure 5 compares the horizontal displacements recorded in the foundation inclinometer (Figure 3) at the end of the wall construction with those achieved in the numerical analysis. The trend of the displacements was captured by the numerical model, even if the maximum horizontal displacement was $20 \%$ lower than that recorded at the end of construction.

According to Santos et al [1] the negative horizontal displacements close to the ground surface are a consequence of the influence of the superficial stiffer soil crust, which restrains horizontal displacements in that region. This phenomenon was not modelled.

The horizontal displacements of the wall face at the end of construction are illustrated in Figure 6 . The results are compared to the values recorded by [1] at the topographic marks located at the wall face. 


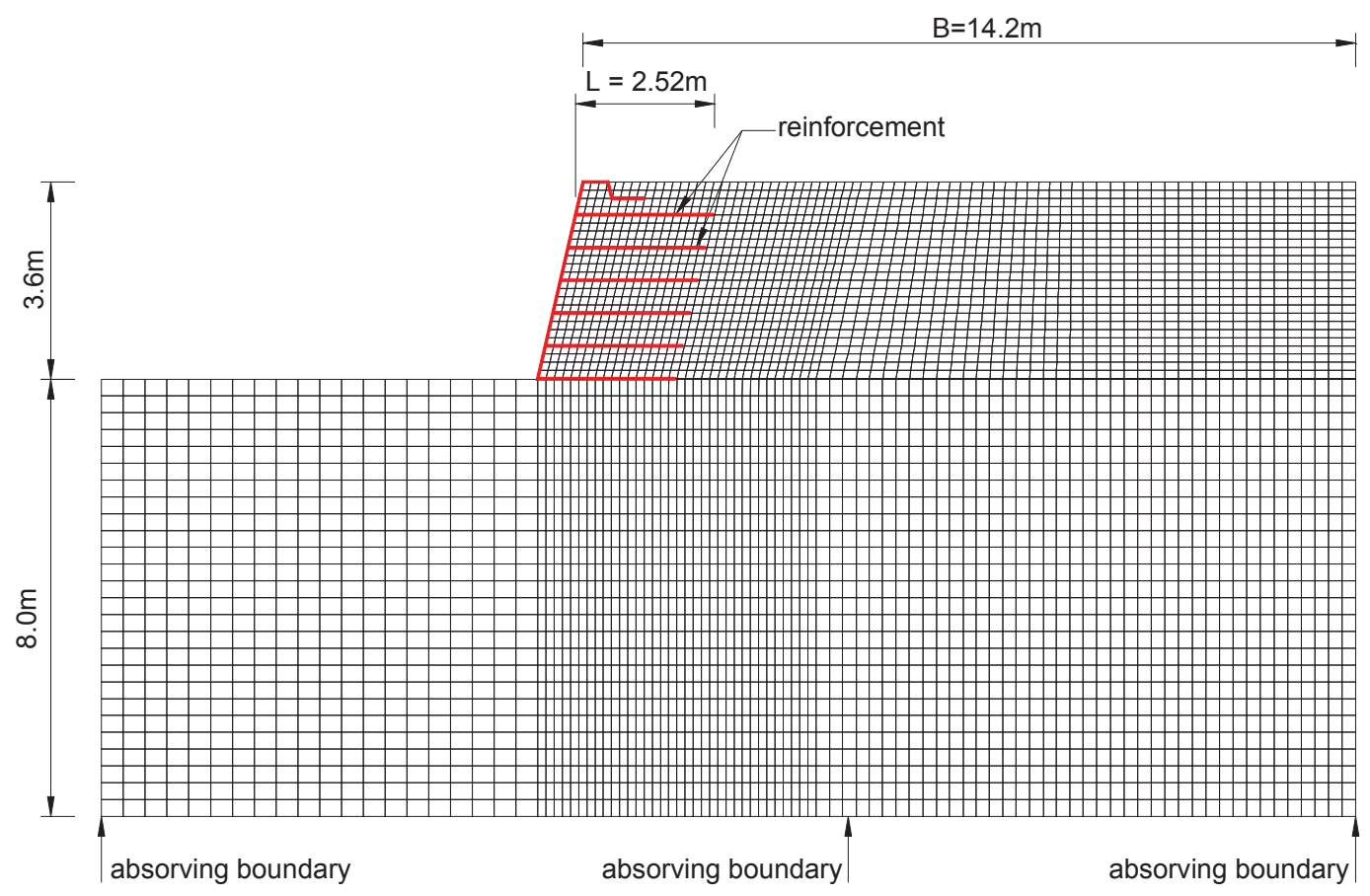

Figure 4: Geometrical properties and numerical grid.

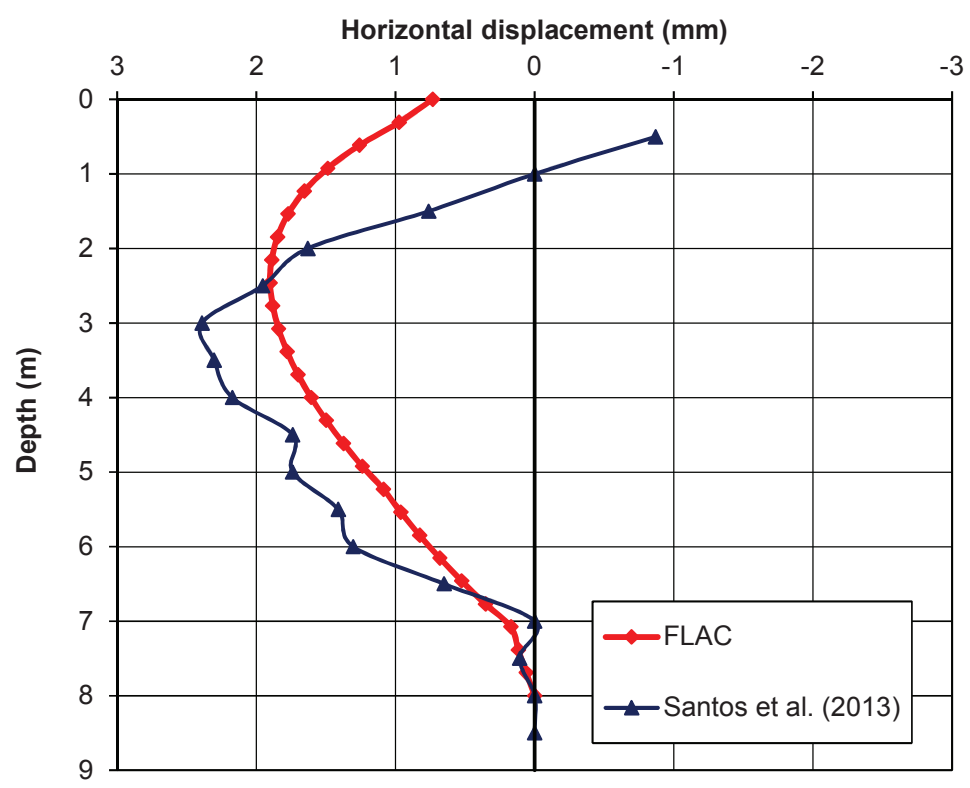

Figure 5: Comparison of horizontal displacements recorded at the foundation inclinometer.

At the end of construction, a maximum outward horizontal displacement of $51 \mathrm{~mm}$ at an elevation of approximately $3 \mathrm{~m}$ was recorded [1]. Close to the crest of the wall a negative horizontal displacement of $107 \mathrm{~mm}$ was measured. This pattern of horizontal displacement was justified by the authors as a consequence of non-uniform deformation of the foundation soil.

The numerical model followed the horizontal displacements of the wall face near the bottom, notwithstanding the pattern of the curve is quite different. The numerical analysis underestimated the horizontal displacements of the wall face. It should be noted, however, that the maximum value of horizontal displacement measured at the end of construction is significant- 
ly greater than the values usually found for structures on strong foundation soils [1]. Local bulging at the face was also observed.

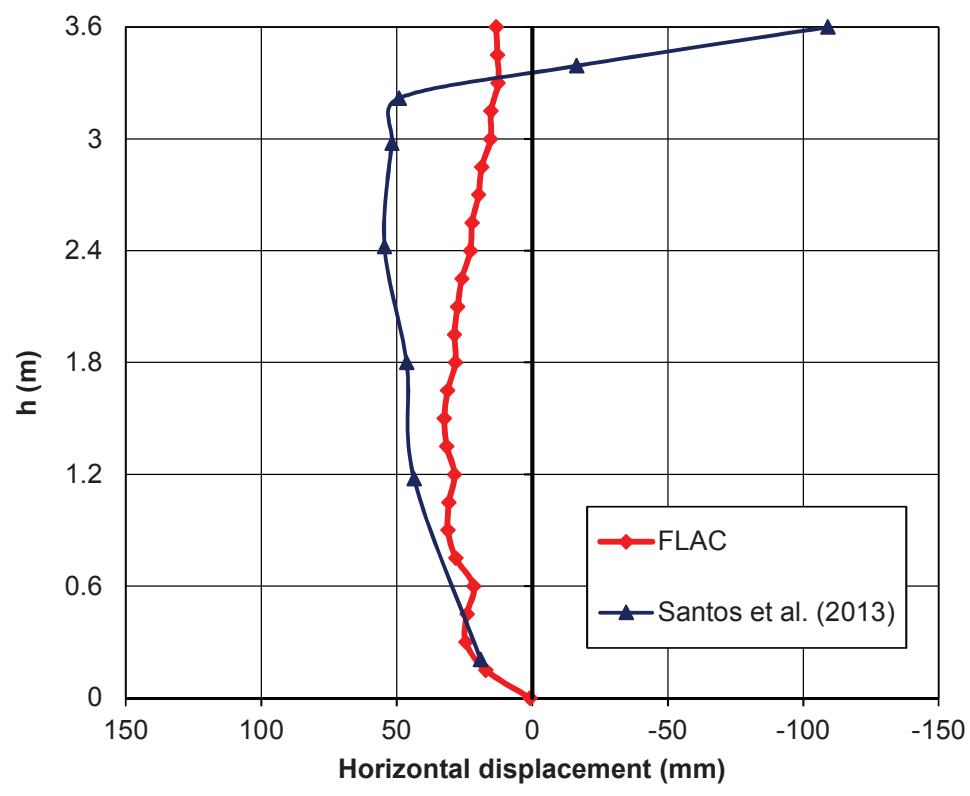

Figure 6: Horizontal displacements of the wall face.

\section{DYNAMIC ANALYSES}

\subsection{General aspects}

The shear strength parameters of the C\&DW reported by [1] are quite distinct from those that are being estimated in a research project under development at University of Porto, Portugal, studying the use of recycled C\&DW as backfill material in geosynthetic reinforced structures.

Results of direct shear tests carried out on fine grain recycled C\&D waste materials were presented by [2]. These authors concluded that C\&DW, properly selected and compacted, could exhibit similar shear strength (even greater) to the backfill materials commonly used in the construction of geosynthetic reinforced structures. The material studied by [2] have shown a peak friction angle of $44.1^{\circ}$ and cohesion value of $17.3 \mathrm{kPa}$. The large displacement shear strength was characterized by a friction angle of $41.2^{\circ}$ and a cohesion of $2.8 \mathrm{kPa}$. The large reduction of the cohesive term for large shear displacements was pointed out as an important aspect to be considered in the design of of geosynthetic reinforced structures constructed with C\&DW as backfill material.

On this basis, it was decided that dynamic analyses should be carried out considering the shear strength parameters estimated for the recycled C\&DW coming from a Portuguese recycling plant.

\subsection{Boundary conditions}

The modelling of geomechanic problems involves media which are better represented as unbounded. Numerical methods are based on the discretization of a finite region, so the appropriate conditions should be enforced at the artificial numerical boundaries. In static analyses, fixed boundaries can be realistically placed at some distance from the region of interest. In dynamic problems, however, such boundary conditions cause the reflection of outward 
propagating waves back into the model and do not allow the necessary energy radiation. The use of a larger model can minimize the problem, however this solution leads to a large computational burden. The alternative is to use absorbing (or quiet) boundaries.

The viscous boundary developed by Lysmer and Kuhlemeyer [6] is used in FLAC. It is based on the use of independent dashpots in the normal and shear directions at the model boundaries. The method is almost completely effective at absorbing body waves approaching the boundary at angles of incidence greater than $30^{\circ}$. For lower angles of incidence, or for surface waves, there is still energy absorption, but it is not perfect. However, the scheme has the advantage that it operates in the time domain [3]. More efficient energy absorption requires the use of frequency-dependent elements, which can only be used in frequency-domain analyses.

The boundary conditions at the sides of the model must account for the free-field motion. These boundaries should be placed at sufficient distances to minimize wave reflections and achieve free-field conditions. For soils with high material damping, this condition can be obtained with a relatively small distance. However, when the material damping is low, the required distance may lead to an impractical model [3]. FLAC has implemented an alternative procedure in which the free-field motion is "enforced". With these boundaries, called freefield boundaries, outward waves originating from the structure are properly absorbed.

The base horizontal boundary also causes the reflection of the waves back into the model. To avoid this reflection FLAC allows the introduction of absorbing boundaries called quiet boundaries.

In order to apply quiet boundaries along the same boundary as the dynamic input, the input motion must be applied as a stress history, because otherwise the effect of the quiet boundary will be nullified [3]. It is suggested the following formula to convert a velocity wave into a shear stress wave:

$$
\tau_{\mathrm{s}}=\mathrm{a}\left(\rho \mathrm{C}_{\mathrm{s}}\right) \mathrm{v}_{\mathrm{s}}
$$

where $\mathrm{a}=$ adimensional factor (being suggested a value of 2 ), $\tau_{\mathrm{s}}=$ applied shear stress, $\rho=$ mass density, $C_{S}=$ speed of $S$-wave propagation and $v_{s}=$ input velocity. The factor of 2 accounts for the fact that the applied stress must be double that observed in an infinite medium, since half the input energy is absorbed by the viscous boundary [3]. However, if the model is shallow, the free surface can cause an increase in the base velocity and an adjustment is necessary to produce the intended input velocity, that is to say, it is necessary to find the value of the factor "a", which gives a velocity record that corresponds to the input velocity.

Figure 7 illustrates the horizontal displacement and velocity records at the base of the model for "a" equal to 1.0 and 2.0, as well as, the curves achieved by integration of the acceleration record (goal). It can be observed that $\mathrm{a}=2.0$ gives displacements and velocities greater than those that are supposed to be introduced in the model (goal). On the other hand, for $\mathrm{a}=1.0$ a good adjustment is achieved.

Prevost [7] demonstrate that at a "silent" boundary $(\mathrm{x}=\mathrm{h})$, the shear stress $\tau(\mathrm{h}, \mathrm{t})$ can be expressed as:

$$
\tau(h, t)=-\rho \operatorname{Cv}(h, t)
$$

where $\rho$ is the mass density, $C$ is the speed of wave propagation and $v(h, t)$ is the velocity at $\mathrm{x}=\mathrm{h}$ for the instant $\mathrm{t}$. Comparing equations (5) and (6), the factor " $\mathrm{a}$ " equal to 1.0 is justified and seems suitable for this model. 

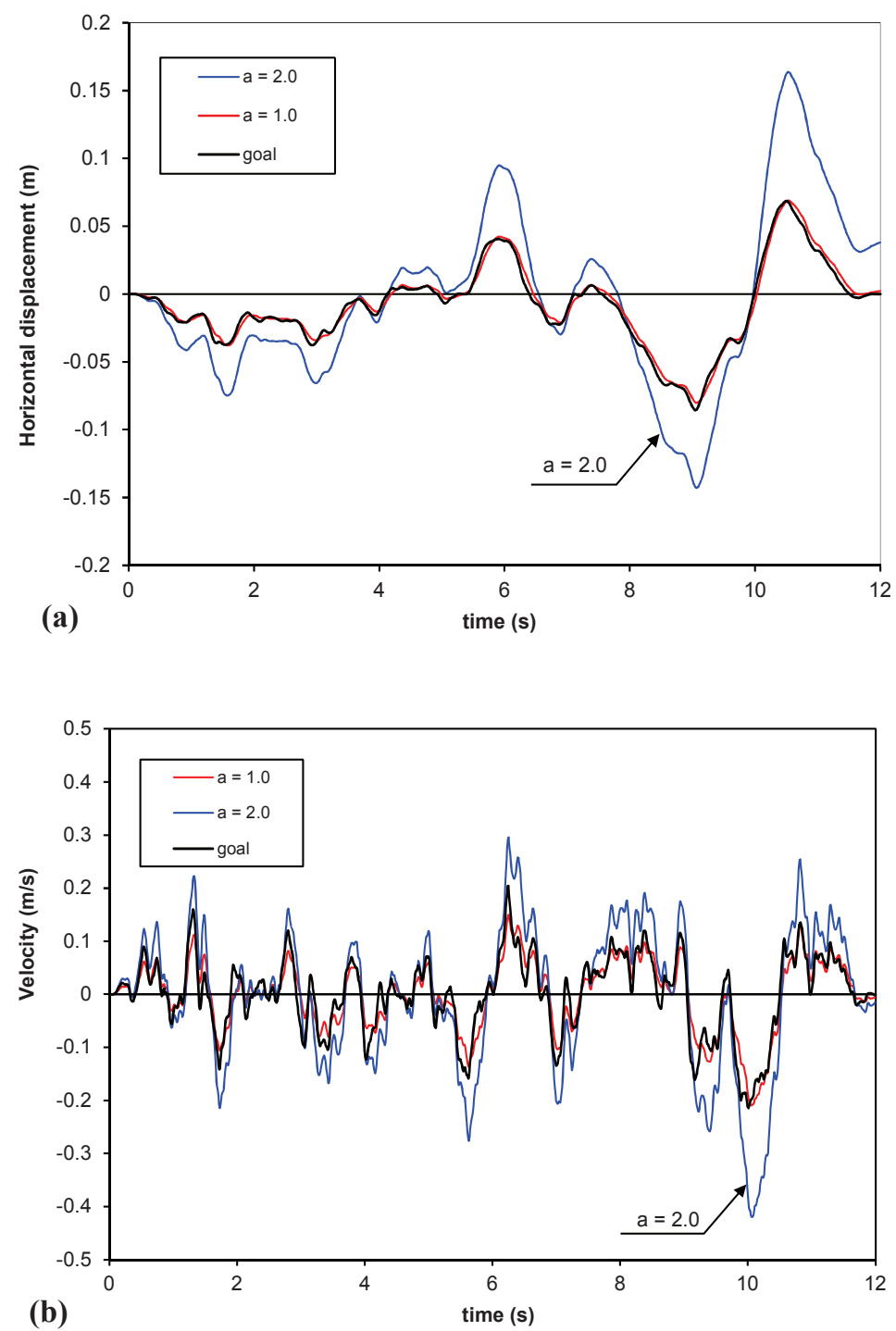

Figure 7: Adjustment to convert a velocity wave into a shear stress wave: a) displacements at the base of the model; b) velocities at the base of the model.

\subsection{Effect of the backfill shear strength properties}

Most of the guidelines indicate explicitly the use of the peak shear strength parameters instead of the residual shear strength parameters in the design of geosynthetic reinforced soil structures. Notwithstanding this approach is not consensual. Jewell [8] suggests the selection a design value for the soil shearing resistance equal to the critical state shear resistance and Leshchinsky [9] proposes a hybrid approach where the critical slip surface is determined based on peak shear strength and the required long-term reinforcement strength is estimated using the residual shear strength parameters.

Regarding the cohesion of the fill material, earlier versions of some guidelines have precluded the cohesive component of the shear strength, but recent editions [10,11] allow the use of cohesive fills. 
As mentioned in 4.1, Vieira et al. [2] have concluded that the shear strength of the recycled C\&DW is frankly encouraging but the cohesion should be used in design with great caution due to the significant reduction for large strain conditions. Based on this evidence, the effect of the values assumed for the backfill shear strength properties was studied in this work. Three numerical analyses were carried out, considering: i) the peak shear strength parameters (Peak values); ii) the peak friction angle and neglecting the cohesion (Peak friction angle); iii) the large displacement shear strength parameters (Residual values).

Figure 8 presents the horizontal displacements of the wall face and the vertical settlements along the wall top at the end of the seismic motion. If the peak shear strength parameters were considered in the numerical analysis, the deformations at the end of the seismic loading would be very small. Nevertheless, if the cohesion is neglected, the backfill deformation will be have some relevance. Local bulging at the wall face, typical of wrapped face structures, is particularly noteworthy (Figure 9). The maximum horizontal displacement of the wall face take place at the crest and it is $8.7 \%$ of the wall height. The maximum settlement at the surface occurs, as expected, near the wall face and it is about $5.7 \%$ of the wall height. Figure 9 illustrates the contours of the horizontal displacements at the end of the earthquake loading for the Peak friction angle analysis, being noticed the large displacements at the crest of the wall.

If the residual shear strength parameters were considered in the analysis, the pattern of the wall deformation is distinct. The local bulging at the wall face is minimized, particularly at the top of the wall, and the surface settlements are also reduced (1.1\% of the wall height). This evidence is quite interesting since the difference between the peak friction angle $\left(44.1^{\circ}\right)$ and the residual friction angle $\left(41.2^{\circ}\right)$ is only $2.9^{\circ}$, which demonstrates the importance of the cohesive term of the shear strength. A cohesion of $2.8 \mathrm{kPa}$ makes a significant difference. Based on this finding, the Peak friction angle analysis was repeated changing the null cohesion by a cohesion of $1 \mathrm{kPa}$. This value has not any physical significance but means, due to the removal of numerical instability, smaller deformations in the retaining backfill (Figure 10).

This numerical change leads to the decrease of $64 \%$ and $69 \%$ on the maximum horizontal displacement at the wall face and maximum settlement, respectively. The differences to the results achieved in the Residual values analysis, obviously, are also diminished.

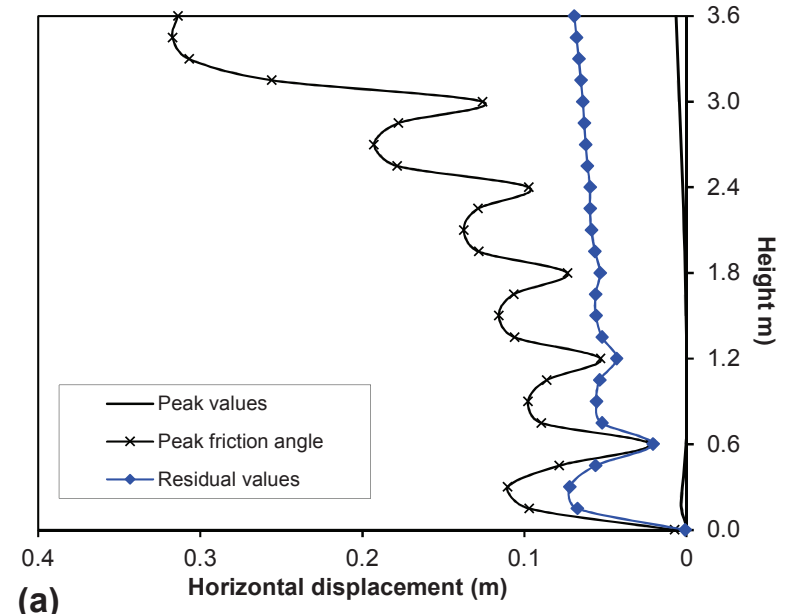

(a)

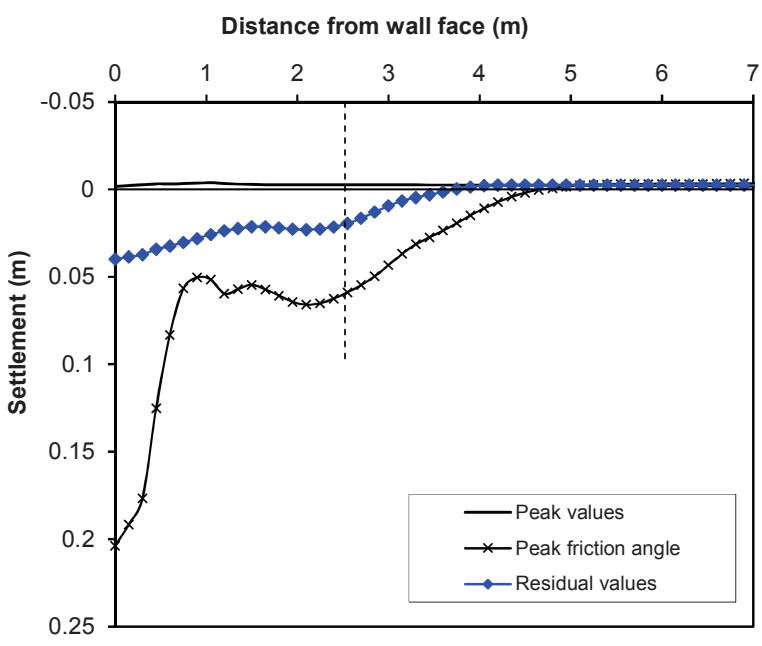

(b)

Figure 8: Effect of the backfill shear strength parameters on: a) horizontal displacements of the slope face; b) settlements at the surface. 


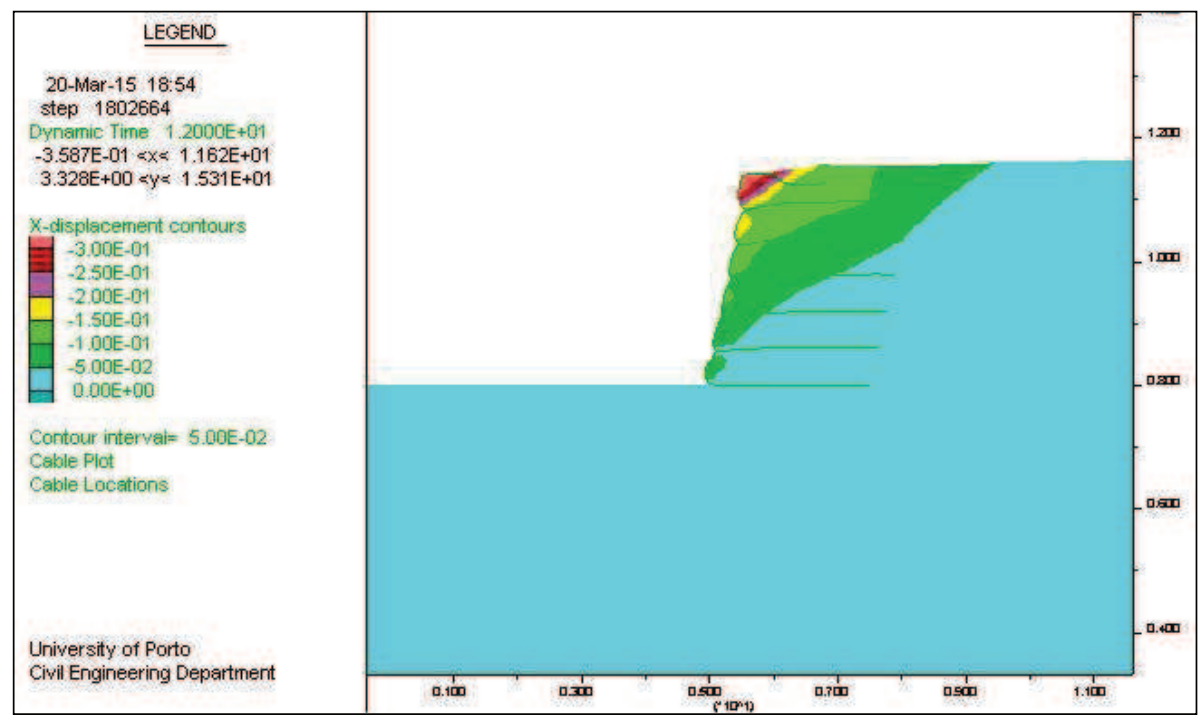

Figure 9: Contours of the seismic horizontal displacements at the end of the earthquake loading (Peak friction angle).
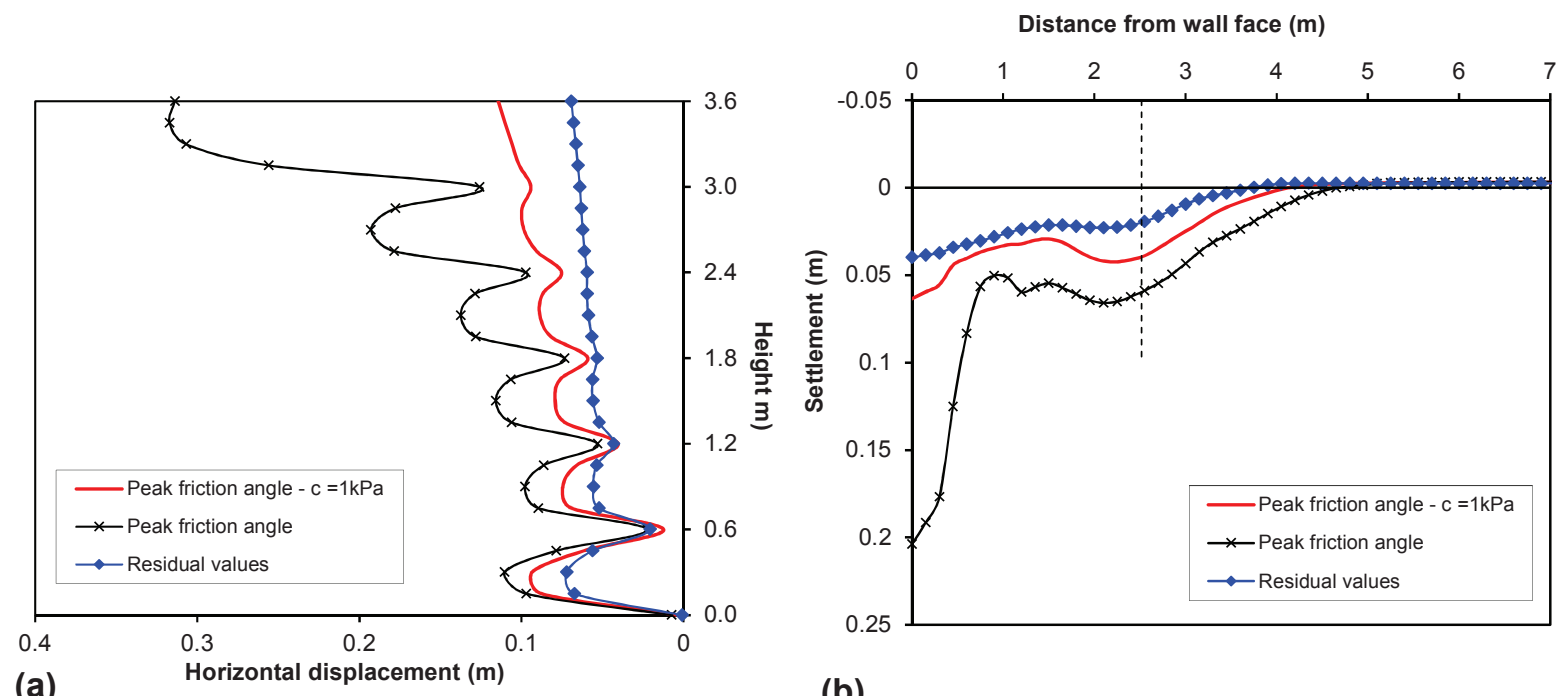

(a)

(b)

Figure 10: Effect of non-zero value of cohesion on: a) horizontal displacements of the slope face; b) settlements at the surface.

To analyze, mainly, the importance of the backfill cohesion in the seismic behaviour of the reinforced wall, a numerical analysis considering the Strain-Softening model for the backfill material was carried out [12]. It was admitted, in the Strain-Softening model, the decrease of the friction angle and cohesion from their peak values to the residual values for shear plastic strains higher than $0.5 \%$.

Figure 11 compares the horizontal displacements of the wall face and the maximum tensile load at the reinforcement layers at the end of the seismic loading for the analyses carried out with Strain-Softening model and with the residual shear strength parameters. As expected, the analysis with the large displacement shear strength parameters during all the numerical simulation, ie, independent of the shear strain, provides greater horizontal displacements. With the Strain-Softening model the bulging effect only occurs at the base of the wall. The maximum horizontal displacement estimated with the Strain-Softening model is $14 \%$ lower than that ob- 
tained with the large displacement shear strength parameters. The difference is maximum at height of $0.9 \mathrm{~m}$ and is about $55 \%$.

The tensile load distribution through the wall height estimated in these analyses is also distinct (Figure 11b). The maximum tensile reinforcement load is quite similar but it is recorded at different geogrid layers.

With regard to the increase of the tensile load during seismic loading, an interesting conclusion was also achieved. Figure 12 illustrates the time histories of the normalized maximum tensile load recorded at the $6^{\text {th }}$ reinforcement layer. The tensile load recorded during the seismic motion was normalized by the tensile load at the end of wall construction $\left(\mathrm{T}_{0}\right)$. With the Strain-Softening model the maximum tensile load recorded at the $6^{\text {th }}$ geogrid layer increased 140 times when compared to the value supported at the end of construction. This finding is justified by the extremely low value supported by this reinforcement layer at the end of construction (note that in this analysis the peak shear strength parameters were considered until $0.5 \%$ of shear plastic strain).

The sudden increase observed in the normalized tensile load at 3.2 seconds after the beginning of the motion (Figure 12b) is probably due the increase of the shear plastic strain, visible near the top of the wall, where the potential failure surface rise the top surface.
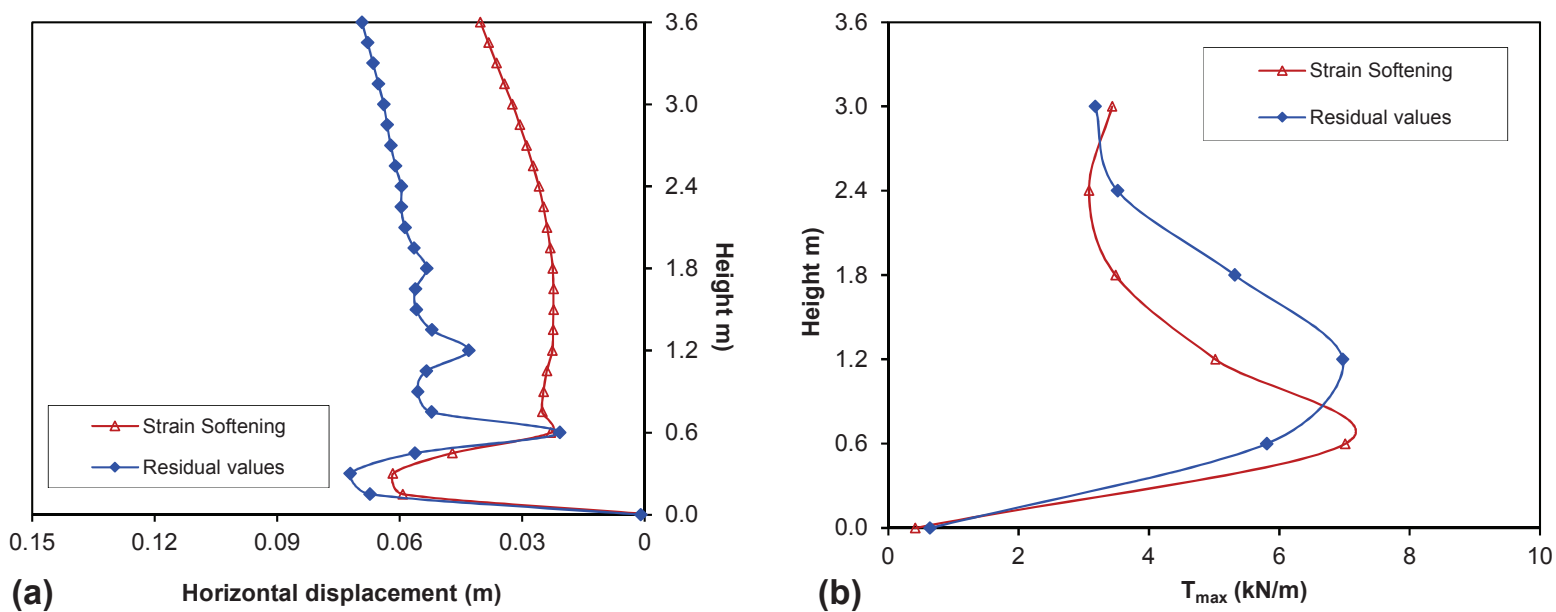

Figure 11: Effect of the backfill constitutive model on: (a) horizontal displacements of the slope face;

(b) maximum reinforcement tensile loads.

\subsection{Effect of the foundation soil properties}

In order to investigate the influence of the foundation soil deformability on the seismic performance of the structure, an additional numerical analyses considering a stiff foundation was carried out. Figure 13 compares the horizontal displacements of the wall face considering the large displacement shear strength parameters (Residual values) with those obtained if the geogrid reinforced wall had been constructed over a stiff foundation.

As expected, a stiff foundation induces smaller deformations being the highest differences observed near the wall base $(22 \%)$. One of the main reasons for this evidence is the occurrence of acceleration amplification for a non-rigid foundation. As shown in Figure 14 when the foundation is deformable an amplification factor greater than 1.5 is recorded at the base of the reinforced wall. 

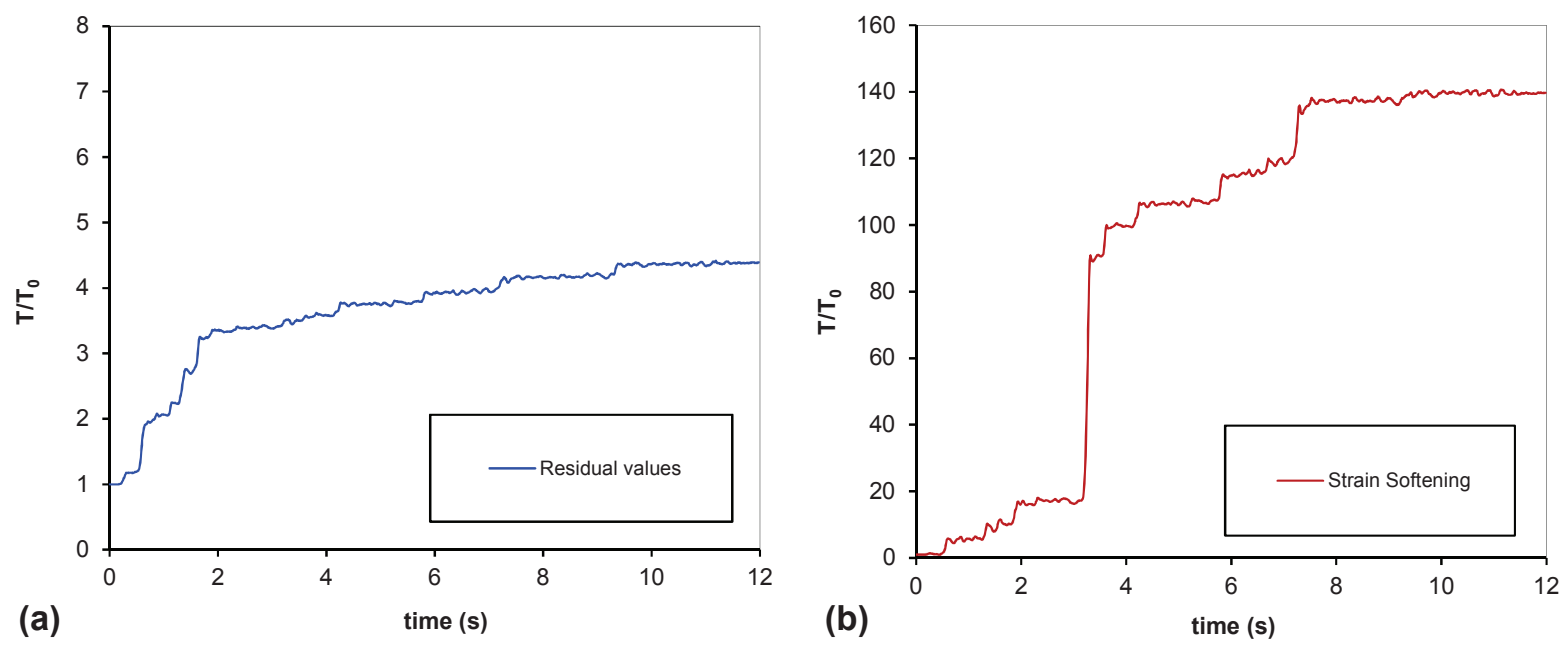

Figure 12: Evolution of the normalized maximum tensile load for the $6^{\text {th }}$ reinforcement layer: (a) analysis with the residual values; (b) analysis with Strain Softening model.

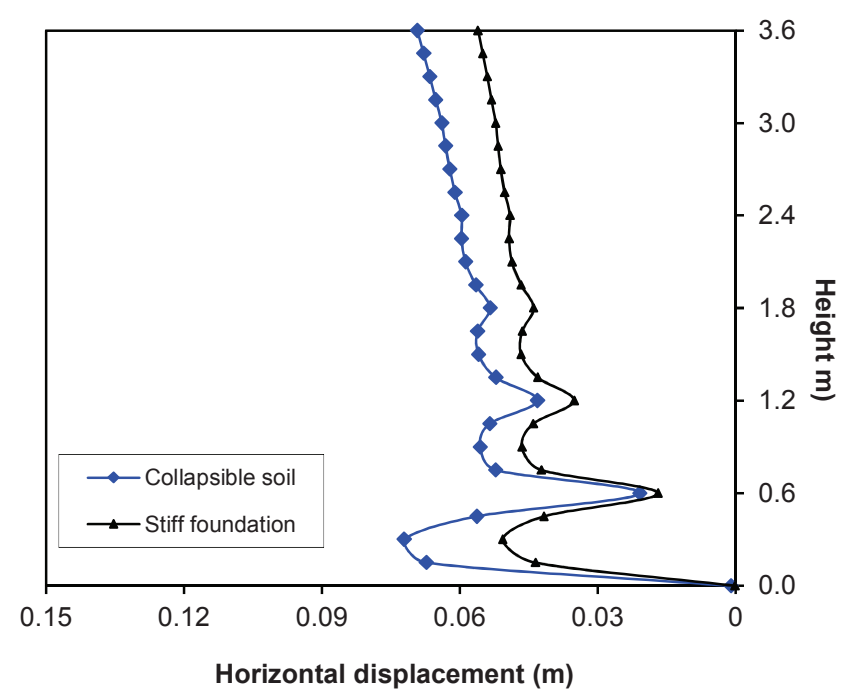

Figure 13: Influence of the foundation stiffness on horizontal displacements of the wall face (Residual values).

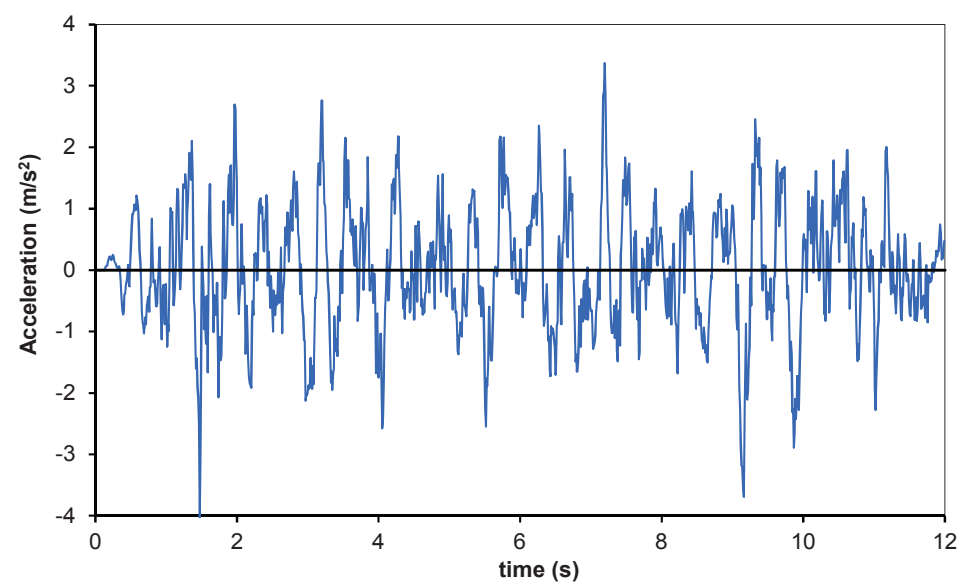

Figure 14: Acceleration record at the wall base for the collapsible soil foundation (Residual values analysis). 


\section{CONCLUSIONS}

The use of recycled Construction and Demolition Wastes as backfill material reduces the use of natural resources and, simultaneously, avoids congesting landfills with inert wastes coming from buildings and other infrastructures. Therefore it is important to study the behaviour of geosynthetic reinforced structures constructed with C\&D materials.

The numerical study herein presented allows to draw the following main conclusions:

- The introduction of quiet boundaries at the base of the model in FLAC implies the conversion of a velocity wave into a shear stress wave, which means that several analyses should be made to achieve the adjustment of the velocity records at the base to the input velocity;

- The use of the large displacements shear strength parameters seems to be the most appropriate approach to model the seismic behavior of geosynthetic reinforced structures constructed with C\&DW as backfill material;

- When neglecting the cohesive term of the backfill shear strength, a null cohesion should be avoided. Due to the numerical instability resulting from zero cohesion, the backfill deformations seems to be overestimated.

- This hypothetical geogrid reinforced wall, constructed with recycled C\&DW, showed a good performance when submitted to an earthquake with moderate magnitude and small focal distance, artificially generated for the greatest seismicity area of Portugal.

\section{ACKNOWLEDGMENTS}

The author would like to thank the financial support of Portuguese Science and Technology Foundation (FCT) and FEDER, through the Research Project: FCOMP-01-0124-FEDER028842, RCD-VALOR - Sustainable application of Recycled Construction and Demolition Wastes (C\&DW) in geosynthetic reinforced structures (PTDC/ECM-GEO/0622/2012).

\section{REFERENCES}

[1] Santos, E.C.G., Palmeira, E.M., and Bathurst, R.J., Behaviour of a geogrid reinforced wall built with recycled construction and demolition waste backfill on a collapsible foundation. Geotextiles and Geomembranes, 39, 9-19, 2013

[2] Vieira, C.S., Pereira, P.P., and Lopes, M.L., Behaviour of geogrid-recycled Construction and Demolition Waste interfaces in direct shear mode. Proceedings of the 10th International Conference on Geosynthetics, ICG 2014; ESTREL Convention Center Berlin; Germany; 21- 25 September 2014.

[3] Itasca, FLAC - Fast Lagrangian Analysis of Continua, in Version 5.00, Itasca Consulting Group, Inc., USA, 2005

[4] Gasparini, D. and Vanmarcke, E., SIMQKE - A computer program for artificial motion generation, in User's Manual and Documentation, Department of Civil Engineering, Massachussets Institute of Technology, 1976.

[5] Fonseca, E.C.A., Palmeira, E.M., and Santos, E.C.G., Numerical analysis of a geogrid reinforced wall built with no-conventional backfill material, Proceedings of the 10th In- 
ternational Conference on Geosynthetics, ICG 2014; ESTREL Convention Center Berlin; Germany; 21- 25 September 2014.

[6] Lysmer, J. and Kuhlemeyer, R.L., Finite Dynamic Model for Infinite Media. J. Eng. Mech., 95(EM4), 859-877, 1969.

[7] Prevost, J.H., DYNA1D - A computer program for nonlinear seismic site response analysis. Technical Documentation, in Technical Report NCEER-89-0025, Princeton University, 1989.

[8] Jewell, R.A., Soil reinforcement with geotextiles. London: Special Publication 123 CIRIA, Thomas Telford. 332p, 1996.

[9] [9] Leshchinsky, D., Design dilemma: use peak or residual strength of soil. Geotextiles and Geomembranes, 19, 111-125, 2001.

[10] AASHTO, LRFD Bridge Design Specifications, 3rd Edition: Washington DC, 2012.

[11] BS 8006, Code of practice for strengthened/reinforced soils and other fills, British Standard Institution, 2010.

[12] Vieira, C.S. and Lopes, M.L., Behaviour of a geosynthetic reinforced steep slope constructed with cohesive backfill under earthquake loading, in ECCOMAS Thematic Conference - COMPDYN 2013: 4th International Conference on Computational Methods in Structural Dynamics and Earthquake Engineering, Proceedings - An IACM Special Interest Conference: Kos Island; Greece; 12 June 2013 through 14 June 2013, 2708-2721. 